\title{
ASPECTOS ANATÔMICOS E FISIOLÓGICOS DE FOLHAS DE Mimosa scabrella DE ÁREAS COM DIFERENTES GRAUS DE SUCESSÃO
}

\author{
Larissa De Bortolli Chiamolera ${ }^{1}$, Alessandro Camargo Ângelo ${ }^{2}$, Maria Regina Boeger ${ }^{3}$, \\ Fernando Correia Araújo ${ }^{4}$ \\ ${ }^{1}$ Bióloga, Dra ${ }^{\mathrm{a}}$, Faculdades Integradas do Brasil, UNIBRASIL, Curitiba, PR, Brasil - laridbc@ gmail.com \\ ${ }^{2}$ Eng. Florestal, Dr., Depto. de Ciências Florestais, UFPR, Curitiba, PR, Brasil - alessandro.angelo@ufpr.br \\ ${ }^{3}$ Bióloga, Dra ${ }^{\mathrm{a}}$., Depto. de Botânica, UFPR, Curitiba, PR, Brasil - rboeger@ufpr.br \\ ${ }^{4}$ Acadêmico de Engenharia Florestal, UFPR, Curitiba, PR, Brasil - fernando.c.araujo@ gmail.com
}

Recebido para publicação: 18/05/2009 - Aceito para publicação: 29/04/2011

\begin{abstract}
Resumo
O objetivo deste trabalho foi verificar a influência de diferentes condições de luminosidade presentes em folhas de Mimosa scabrella Benthan plantadas em áreas com diferentes graus de sucessão nas margens do Reservatório Iraí, PR. Foram avaliados aspectos morfológicos (área foliar, peso seco, área foliar específica), anatômicos (espessuras de cutícula, epiderme adaxial, parênquima paliçádico, parênquima lacunoso, epiderme adaxial e espessura total), fisiológicos (taxa de fotossíntese, condutância estomática e transpiração) e desenvolvimento das plantas (altura, diâmetro e sobrevivência até os 18 meses). Para os parâmetros morfológicos, $M$. scabrella apresentou diferença significativa para a área foliar específica, que foi maior para os indivíduos da capoeira. Diferenças significativas foram encontradas para a espessura da epiderme adaxial e do parênquima paliçádico. A epiderme adaxial foi maior na área de capoeira, enquanto que o parênquima paliçádico maior na área aberta. Indivíduos da área aberta apresentaram maior taxa de transpiração e condutância estomática. Tanto a altura quanto o diâmetro não mostraram diferença significativa entre as áreas. A sobrevivência foi considerada insatisfatória para ambas as áreas, porém foi ligeiramente maior na capoeira. Esses resultados, aliados ao comportamento natural da espécie, sugerem que M. scabrella deve ser implantada em densidades maiores.
\end{abstract}

Palavras-chave: Morfoanatomia foliar; fisiologia, variação de luz; recuperação de área degradada; silvicultura de espécies nativas.

\begin{abstract}
Anatomical and physiological features of Mimosa scabrella leaves growing on areas with different succession stages This study aims to evaluate the influence of light conditions at different stages of succession in leaves of Mimosa scabrella Benthan planted in Iraí's water reservoir margins, State of Paraná, Brazil. We evaluated leaf morphology (area, dry weight, specific area), anatomy (cuticle thickness, adaxial epidermis, palisade parenchyma, parenchyma spongy, adaxial epidermis and total thickness), physiology (photosynthesis rate, stomatal conductance, transpiration) and plant growth (height, diameter) and survival up to age of 18 months. Plants of Mimosa scabrella of natural regeneration showed greater leaf specific area than those of planted individuals. Significant differences were found on thickness of the adaxial epidermis and palisade parenchyma. The adaxial epidermis was higher in regenerating area, whereas the palisade parenchyma was higher in open field. Plants of open field presented higher values of transpiration and stomatal conductance. Concerning height and diameter growth, plants of both areas showed no significant differences. Survival was considered unsatisfactory for both areas, but was slightly higher in regenerating area. According to $M$. scabrella behavior in natural conditions, the results suggest that this species must be implanted in greater densities.

Keywords: Leaf morphology; leaf anatomy; physiology; light; land recuperation; native tree species.
\end{abstract}

\section{INTRODUÇÃO}

A demanda pelo conhecimento acerca do comportamento de espécies nativas é crescente em função da potencialidade econômica dessas espécies, bem como devido ao aumento da importância da atividade de restauração de ambientes. Isso verificou-se principalmente a partir da década de 80 , pelo

FLORESTA, Curitiba, PR, v. 41, n. 3, p. 435-450, jul./set. 2011. 
desenvolvimento da ecologia da restauração como ciência, que passou a incorporar um conceito extremamente importante, que é o da sucessão ecológica. Ricklefs (2003) define a sucessão ecológica como sendo a substituição de populações num habitat através de uma sequência repetida de estágios, ou seja, é a sequência de mudanças iniciada pela perturbação até atingir a última associação de espécies, formando a comunidade clímax. Rodrigues e Gandolfi (1998) complementam, afirmando que esse processo caracteriza-se principalmente por gradual aumento e substituição de espécies no tempo, em função das diferentes condições ambientais que vão se estabelecendo, ou seja, ocorre uma substituição de espécies de grupos ecológicos ou categorias sucessionais (pioneiras, secundárias iniciais, secundárias tardias ou clímax).

Existe uma grande variação na resiliência dos ambientes em processo de recuperação, forçando a concepção de projetos distintos. Nesse sentido, Campelo (1998) afirma que uma das grandes dificuldades de um projeto de revegetação de áreas degradadas é que não existem fórmulas prontas, e a intervenção técnica deve se basear no potencial de recuperação do ecossistema, buscando ajudar os processos naturais. Baseado nisso, Durigan et al. (2004) afirmam que, atualmente, o plantio de espécies arbóreas é visto como apenas o primeiro passo ao longo do caminho para uma floresta autorrenovável, sendo que o papel desse plantio é, principalmente, melhorar as condições de solo e o microclima, para favorecer os processos naturais de regeneração.

A escolha adequada das espécies que devem ser usadas é um dos fatores primordiais para o sucesso desses projetos. Assim, conhecer o comportamento de espécies nativas no campo se mostra mais uma vez uma necessidade urgente. Reis et al. (2003), citando Yarranton e Morrison (1974), afirmam que muitas vezes a ocupação de áreas por espécies arbóreas pioneiras propicia a formação de pequenos agregados de outras espécies ao redor das espécies colonizadoras, acelerando o processo de sucessão. Esse aumento do ritmo de colonização a partir de uma espécie promotora foi denominado de nucleação, e é um processo de extrema importância para a revegetação de áreas degradadas. Tais espécies atraem pássaros e morcegos que procuram proteção, repouso e alimentos, e assim propiciam o transporte de sementes de espécies mais avançadas na sucessão, contribuindo para a diversificação do processo sucessional de comunidades florestais secundárias.

Em cada estágio sucessional existem grupos de espécies que otimizam as condições do ambiente. Diante disso, foram criados grupos de classificação dessas espécies, tal como as de Budowski (1965) e Denslow (1980). A classificação de espécies em grupos ecológicos define o papel delas na sucessão secundária e dentro do ecossistema florestal, auxiliando na sua estratificação biológica (KAGEYAMA, 1987). Porém essa classificação é uma questão difícil, e em consulta à literatura percebe-se que a disposição de determinadas espécies dentro dos grupos ecológicos nem sempre é unânime entre diferentes autores. Mesmo que uma espécie seja enquadrada por alguns autores em um dos grupos sucessionais, é comum a constatação de respostas dessas espécies que fogem ao determinado para os grupos. Muito mais do que uma classificação, compreender quais são os mecanismos morfológicos e fisiológicos que essas espécies possuem, no campo, em resposta a fatores ambientais é algo que merece muita atenção.

$\mathrm{O}$ estudo das variações estruturais anatômicas de uma planta tenta responder a essas questões, pois mostra a relação entre a morfologia da planta e o ambiente, ou seja, tem como objetivo principal estudar o desenvolvimento de mudanças em características funcionais e estruturais dos indivíduos em resposta a fatores ambientais a que estão expostos (GRIME; MACKEY, 2002). Dessa forma, mostra a habilidade que um genótipo tem de expressar diferentes fenótipos em resposta a distintos ambientes (CORRÊA, 2004).

Um dos principais fatores utilizados para a classificação das espécies em grupos ecológicos é a quantidade de luz que elas necessitam para o seu crescimento. Vários autores afirmam que a luz é um dos fatores mais importantes no controle do desenvolvimento de plântulas de espécies arbóreas em florestas tropicais (POORTER, 2001). Muitas espécies são capazes de se aclimatar quando submetidas a uma mudança nas condições de luz, sendo que essa aclimatação é variável de espécie para espécie e pode depender do gradiente de luz que as espécies recebem (POORTER, 1999) ou de seu estágio sucessional (STRAUSS-DEBENEDETTI; BAZZAZ, 1996). Essa variação nas condições lumínicas é constatada, principalmente, nos componentes foliares (DICKSON, 2000).

Mimosa scabrella é popularmente conhecida como bracatinga e ocorre de forma natural nos estados de Minas Gerais, São Paulo, Rio de Janeiro, Paraná, Santa Catarina e Rio Grande do Sul, no Brasil, sendo uma espécie característica do planalto sul-brasileiro e exclusiva da vegetação secundária da 
Floresta Ombrófila Mista, nas formações Montana e Alto-Montana. Nos pinheirais primários não perturbados, a bracatinga é pouco abundante (CARVALHO, 2003). Lorenzi (1992) afirma que, por ser uma planta pioneira de rápido crescimento, não deve faltar nos plantios de áreas degradadas de composições mistas. Carpanezzi (1997) reforça essa ideia, afirmando que a bracatinga recobre rapidamente o solo nu, inibindo a invasão de vegetação herbáceo-arbustiva e favorecendo o crescimento de espécies tolerantes ao sombreamento. Essa essência foi bastante utilizada no sul do país para recuperação de áreas de mineração, onde o solo se encontrava profundamente degradado (FERREIRA et al., 2002), pois é uma espécie que produz grande quantidade de serapilheira, retornando ao solo muitos nutrientes (BERTALOT et al., 2004). Carpanezzi et al. (1984) comprovaram que a deposição de biomassa da bracatinga retorna ao solo mais de 8 mil kg de matéria orgânica seca, $200 \mathrm{~kg}$ de nitrogênio e $15 \mathrm{~kg}$ de potássio por hectare por ano. Além disso, Ferreira (1983) afirma que também pode ser usada para recomposição de matas ciliares, desde que não ocorra encharcamento e inundação. Outro fato importante com relação à bracatinga é que o aparecimento dos botões florais dá-se em março e o florescimento de junho a setembro, nos estados do Paraná e Santa Catarina, em julho no estado de São Paulo e de julho a outubro no Rio Grande do Sul (CARVALHO, 2003), proporcionando o fornecimento de néctar e pólen durante o inverno, aspecto importante para a apicultura e para a manutenção de polinizadores na área em uma época com pouca oferta de alimento.

O objetivo deste trabalho foi avaliar a resposta morfoanatômica e fisiológica de M. scabrella após 18 meses de implantação em condições distintas de luminosidade, considerando como fator de variação áreas com diferentes graus de sucessão nas margens do Reservatório Iraí-PR, no momento do estabelecimento do experimento.

\section{MATERIAL E MÉTODOS}

As amostras foliares foram obtidas num plantio realizado nas margens do Reservatório do Iraí, (25'24'15" de latitude sul, 49 $08^{\prime} 38^{\prime \prime}$ de longitude oeste), situado entre os municípios de Pinhais, Piraquara e Quatro Barras (Paraná) e a $890 \mathrm{~m}$ de altitude. O rio Iraí pertence à bacia hidrográfica do rio Iguaçu e tem por finalidade suprir, com seus $58.000 .000 \mathrm{~m}^{3}$, a demanda hídrica da região (CARNEIRO et al., 2005).

Segundo dados fornecidos pelo Simepar, desde a implantação do experimento no campo (dezembro/2005) até a coleta das folhas (junho de 2007), a área de estudo apresentou temperatura média de $17,9^{\circ} \mathrm{C}$, sendo o mês mais quente março de $2007\left(21,7^{\circ} \mathrm{C}\right)$ e o mês mais frio maio de $2006\left(13,6^{\circ} \mathrm{C}\right)$. O mês mais chuvoso foi janeiro de 2007, com $234,2 \mathrm{~mm}$, e o mês menos chuvoso foi junho de 2007 , com $1,4 \mathrm{~mm}$, com precipitação média do período de $82,5 \mathrm{~mm}$. A umidade relativa do ar apresentou média para o período de $84,6 \%$, com extremos para o mês de abril de 2007 , que apresentou $90 \%$, e o mês de agosto de 2006, com $75 \%$. Segundo Köppen, o clima da região é considerado subtropical úmido mesotérmico (Cfb) (MAACK, 1981).

A vegetação ocorrente na região se enquadra na unidade fitogeográfica Floresta Ombrófila Mista, na qual coexistem representantes das floras tropical e temperada, com predomínio do pinheiro-doparaná (Araucaria angustifolia (Bertol.) Kuntze). Nessa unidade, encontra-se inserida uma formação natural de campos, citada por Maack (1981), com presença de capões constituídos por flora típica da Floresta Ombrófila Mista (CURCIO et al., 2007).

Para a instalação do experimento, foi escolhida uma área do reservatório que apresentava diferentes graus de sucessão, ou seja, uma área onde a regeneração espontânea apresentava-se ainda predominantemente constituída por gramíneas (“Área Aberta”), e a outra, uma área com a presença de uma capoeirinha, que segundo a Classificação da Vegetação Brasileira do IBGE (VELOSO, 1991), é uma vegetação que apresenta um estrato arbustivo mais desenvolvido, com poucas plantas herbáceas e muitas lenhosas de baixo porte, como o gênero Baccharis ("Área de Capoeira"). Para a caracterização da intensidade luminosa no momento da implantação do experimento, foi realizada a amostragem de 30 pontos nas duas áreas, com o auxílio de um luxímetro, caracterizando a área aberta (114.400 lux) com praticamente o dobro da intensidade luminosa disponível na área de capoeira (57.66667 lux).

O solo foi classificado como CAMBISSOLO HÚMICO distrófico gleico de textura argilosa, de acordo com o Sistema de Classificação de Solos da Empresa Brasileira de Pesquisa Agropecuária (EMPRESA BRASILEIRA DE PESQUISA AGROPECUÁRIA (EMBRAPA), 1999). O local do plantio possui uma declividade entre 4 e $7 \%$ e foi configurado como semi-hidromórfico (CURCIO et al., 2007). 
As espécies plantadas na área foram Mimosa scabrella Benth: Mimosaceae (bracatinga), Schinus terebinthifolius Raddi: Anacardiaceae (aroeira), Podocarpus lambertii Klotzsch ex Eichler: Podocarpaceae (pinheiro-bravo), Luehea divaricata Mart.: Tiliaceae (açoita-cavalo) e Escallonia montevidensis (Cham. \& Schltdl.): Saxifragaceae (canudo-de-pito). A seleção dessas espécies teve como critério o fato de serem nativas na região e aptas às condições dos solos do local de plantio. Outros critérios de seleção foram a rusticidade e a taxa de crescimento de algumas espécies (pioneiras, com crescimento rápido, formação de biomassa, sombreamento e habitat para fauna, incluindo-se aí outros estádios de sucessão ecológica).

As mudas implantadas na área de estudo foram provenientes dos seguintes viveiros: Instituto Ambiental do Paraná (IAP), Embrapa Florestas (Colombo) e Viveiro do Projeto Iraí, localizado na Fazenda Canguiri, da UFPR. As sementes utilizadas para a produção das mudas foram colhidas em municípios ao redor da área, obedecendo a critério de seleção de coleta para as diferentes espécies de acordo com Nogueira (2002). O tempo de permanência das mudas no viveiro variou conforme a espécie, porém a média foi de quatro meses. No momento da implantação das mesmas no campo, a bracatinga estava com altura média de $20 \mathrm{~cm}$.

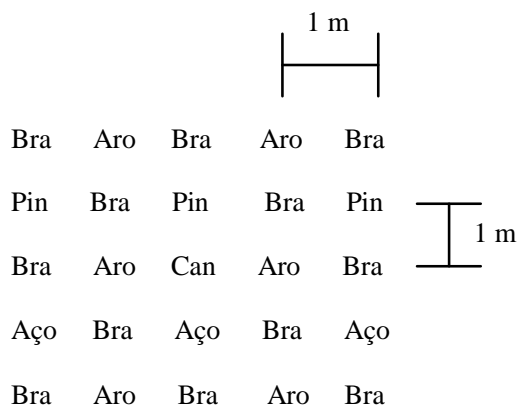

Figura 1. Modelo de distribuição das espécies (subparcela). (Bra $=M$. scabrella; Aro $=S$. terebinthifolius $;$ Pin $=P$. lambertii $;$ Aço $=$ L. divaricata $;$ Can $=$ E. montevidensis $)$.

Figure 1. Model of distribution of species (sub-plots). (Bra $=$ M. scabrella; Aro $=$ S. terebinthifolius; Pin $=$ P. lambertii $;$ Aço $=$ L. divaricata $; \mathrm{Can}=$ E. montevidensis $)$.

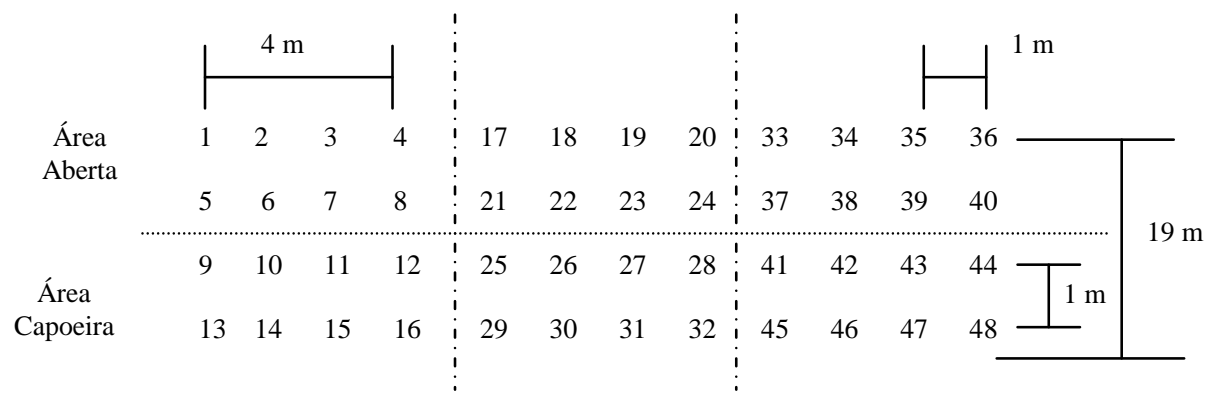

Reservatório Iraí

Figura 2. Modelo de disposição das parcelas. Os números correspondem às parcelas, que são formadas pelas espécies já mostradas na figura 1.

Figure 2. Model of plot's provision. The numbers correspond to the plots, which are formed by species already shown in figure 1 .

Para efeito de obtenção de repetições, foi definido um modelo (parcelas) de disposição das espécies (Figura 1). Essas parcelas foram dispostas 48 vezes, sendo que 24 parcelas estavam em área considerada "aberta" e 24 parcelas em "área de capoeira" (Figura 2). O espaçamento utilizado (1 x $1 \mathrm{~m}$ ) foi uniforme para as duas áreas. Cada parcela continha 12 indivíduos de $M$. scabrella, além de seis de $S$. terebinthifolius, três de $P$. lambertii, três de L. divaricata e um indivíduo de E. montevidensis. Dessa forma, o número total de indivíduos por espécie foi de 576, 288, 144, 144 e 48, respectivamente, para $M$. 
scabrella, S. terebinthifolius, P. lambertii, L. divaricata e E. montevidensis, totalizando 1.200 indivíduos para a área total avaliada.

O plantio foi realizado nos dias 14 e 15 de dezembro de 2005. Para o plantio das mudas na área de capoeira, somente foram abertas as covas, sem intervenção na vegetação já existente, não sendo realizada adubação e nem a supressão de plantas competidoras, apenas o coroamento aos 12 meses. Após um mês de implantação das mudas, foi realizado um replantio, para substituição dos espécimes perdidos.

Aos seis, doze e dezoito meses de implantação, foram realizadas medições de diâmetro do colo e altura de todos os indivíduos das espécies do estudo, utilizando-se paquímetro e trena, respectivamente, sendo também realizada análise de sobrevivência das plantas.

Em junho de 2007, foi realizada a coleta das folhas para a análise da morfologia foliar (mudas com 18 meses de campo). Para cada área com condição de luminosidade diferente (área aberta e capoeira), foram coletadas cinco folhas de cada indivíduo, localizadas entre o quarto e o sexto nó no sentido ápice-base. Destas, três folhas de cada indivíduo $(\mathrm{n}=90)$ foram prensadas totalmente expandidas entre papel jornal e desidratadas em estufa a $65^{\circ} \mathrm{C}$ durante três dias, até atingirem peso constante para a mensuração dos seus respectivos pesos secos, em balança de precisão. A partir dessas folhas secas, a área foliar foi estimada através da imagem digitalizada em escâner de mesa acoplado a computador, com o auxílio do programa Sigma Scan-Pro versão 5.0 (SPSS Inc., Chicago, IL, USA, 1995). Posteriormente, a área foliar específica $(\mathrm{AEF})$ foi calculada de acordo com a seguinte relação: $\mathrm{AEF}=$ área foliar/peso seco $\left(\mathrm{cm}^{2} \cdot \mathrm{g}^{-1}\right)$ (WITKOWSKI; LAMONT, 1991).

Como a bracatinga apresenta folha composta, para o cálculo da área foliolar foi considerado o terceiro folíolo direito, interpretado como uma folha simples (BONGERS; POPMA, 1990).

Para a análise da anatomia foliar, em cada área, duas folhas de cada indivíduo $(\mathrm{n}=60)$ foram fixadas em F.A.A. 50 (formaldeído, ácido acético, etanol 50\%, 1:1:18 v/v) (JOHANSEN, 1940) e preservadas temporariamente em etanol 50\%. Posteriormente foram obtidas secções transversais da região do terço médio da folha com auxílio de lâmina de barbear. As secções foram clarificadas com hipoclorito de sódio $20 \%$, coradas com azul de toluidina $1 \%$ e montadas entre lâmina e lamínula. Foram medidos, com o auxílio de ocular micrometrada, as espessuras do parênquima paliçádico, do parênquima esponjoso, da epiderme (abaxial e adaxial) e da cutícula, além da espessura total de limbo.

Para a determinação das variáveis fisiológicas (taxa fotossintética, condutância estomática, taxa de transpiração), foram realizadas medidas no terceiro folíolo do terço apical em 30 indivíduos de cada uma das áreas. As avaliações foram feitas com o auxílio de um analisador portátil de fotossíntese (Portable Photosynthesis System, modelo LC pró+, Dynamax, USA). No momento da coleta das folhas, foi feita a caracterização lumínica das áreas, utilizando-se dados da taxa fotossinteticamente ativa (PAR), caracterizando a área aberta com 1387,53 $\mu \mathrm{mol} / \mathrm{m}^{2} / \mathrm{s}$ e a área de capoeira com $935,27 \mu \mathrm{mol} / \mathrm{m}^{2} / \mathrm{s}$.

Para todas as variáveis, foram calculadas as médias e os respectivos desvios-padrão. Para a análise dos tratamentos, foi utilizado Teste t para comparar as médias das características morfológicas ao nível de 5\% de probabilidade com o auxílio do programa STATISTICA versão 6.0 (STATSOFT, INC. TULSA, OK, USA, 1998).

\section{RESULTADOS, DISCUSSÃO E CONCLUSÕES}

As folhas de M. scabrella apresentaram uma média de 6,9 folíolos na área aberta e 7,17 folíolos na área de capoeira, diferença esta não significativa (Tabela 1). Esses dados estão de acordo com Carpanezzi (1988), o qual afirma que a bracatinga possui folha bipinada com 5 a 7 pares de pinas.

Os valores médios para as características morfológicas podem ser vistos na tabela 1. Tanto a área foliar quanto o peso seco não mostraram ter diferença significativa entre os tratamentos. Esse resultado contradiz alguns autores (KLICH et al., 2000), que mostraram que espécies que se desenvolvem sob alta intensidade luminosa tendem a apresentar folhas menores, para proporcionar aumento na convecção de calor dissipado (ALVES, 2006), de modo a evitar o superaquecimento dentro da folha e impedir a desidratação pelas altas taxas de transpiração (KLICH et al., 2000) e a fotodestruição da clorofila (AHSTON; BERLYN, 1992). Porém Dale (1988) afirma que o aumento ou não da área foliar está relacionado com o grupo ecológico a que a espécie pertence. Em espécies heliófitas, a área foliar tende a aumentar com a elevação da radiação solar, ao passo que em espécies tolerantes a sombra a área foliar tende a aumentar somente em condições de baixa disponibilidade de radiação solar. 
Tabela 1. Valores médios, respectivos desvios-padrão (entre parênteses) e coeficientes de variação (cv\%) das características morfológicas $(\mathrm{n}=90)$ para folhas de Mimosa scabrella nos diferentes tratamentos. Letras diferentes para mesma variável representam diferenças estatisticamente significativas entre os tratamentos testados (teste $t, p<0,05$ ).

Table 1. Averages, standard deviations (in parentheses) and coefficients of variation (cv\%) of morphological characteristics $(\mathrm{n}=90)$ for leaves of Mimosa scabrella in different treatments. Different letters for the same variable represent statistically significant differences among the treatments tested ( $t$ test, $\mathrm{p}<0,05)$.

\begin{tabular}{lcccc}
\hline Características & Área aberta & CV (\%) & Capoeira & CV (\%) \\
\hline Número de folíolos & $6,90( \pm 1,61) \mathrm{a}$ & 23,30 & $7,17( \pm 1,42) \mathrm{a}$ & 19,87 \\
Área foliar $\left(\mathrm{cm}^{2}\right)$ & $2,45( \pm 1,26) \mathrm{a}$ & 51,56 & $2,54( \pm 1,22) \mathrm{a}$ & 47,94 \\
Peso seco $(\mathrm{g})$ & $0,02( \pm 0,01) \mathrm{a}$ & 60,14 & $0,018( \pm 0,01) \mathrm{a}$ & 53,85 \\
Área específica foliar (AEF) $\left(\mathrm{cm}^{2} \cdot \mathrm{g}^{-1}\right)$ & $130,21( \pm 22,55) \mathrm{b}$ & 17,32 & $142,63( \pm 20,50) \mathrm{a}$ & 14,37 \\
\hline
\end{tabular}

Em contrapartida, a área específica foliar diferiu estatisticamente, sendo maior nas folhas da capoeira. Essa informação está de acordo com alguns autores (GONÇALVES et al., 2005), os quais afirmam que, geralmente, os maiores valores de área específica foliar ocorrem em folhas de sombra, devido ao aumento na expansão foliar, resultado da maximização da captura da luz, já que esta se encontra em menor quantidade. Boeger et al. (2006) citam que espessura e área específica foliar são consideradas as principais características indicadoras da taxa de crescimento e das estratégias do uso de recursos pelas plantas. Folhas com altos valores de AEF são mais produtivas, apesar de serem mais vulneráveis à herbivoria, e geralmente ocorrem em ambientes com maior disponibilidade de recursos. A AEF pode ser afetada diretamente pela massa seca, pela espessura do mesofilo, pelos tecidos de sustentação e pelo teor de água (MEZIANI; SHIPLEY, 1999). Isso pode ser observado para a bracatinga, já que o peso seco das folhas não variou entre os tratamentos, sugerindo que outro fator possa estar contribuindo para essa diferença observada na AEF.

Tabela 2. Valores médios e respectivos desvios-padrão (entre parênteses) e coeficientes de variação (cv\%) das espessuras dos tecidos componentes da lâmina foliar de Mimosa scabrella nos diferentes tratamentos. $(n=60)$. Letras diferentes para mesma variável representam diferenças estatisticamente significativas entre os tratamentos testados (teste $t, p<0,05$ ).

Table 2. Mean values and standard deviations (in parentheses) and coefficients of variation (cv\%) of the tissue thickness of the components the Mimosa scabrella's leaf in different treatments. $(n=60)$. Different letters for the same variable represent statistically significant differences among the treatments tested ( $t$ test, $\mathrm{p}<0,05)$.

\begin{tabular}{lcccc}
\hline Espessura dos tecidos $(\boldsymbol{\mu m})$ & Área aberta & $\mathbf{C V}(\%)$ & Capoeira & CV $(\%)$ \\
\hline Cutícula & $3,57( \pm 1,20) \mathrm{a}$ & 33,61 & $3,97( \pm 1,36) \mathrm{a}$ & 34,35 \\
Epiderme adaxial & $11,27( \pm 2) \mathrm{b}$ & 17,77 & $12,73( \pm 2,62) \mathrm{a}$ & 20,60 \\
Parênquima paliçádico & $65,69( \pm 13,02) \mathrm{a}$ & 19,81 & $60,77( \pm 10,35) \mathrm{b}$ & 17,03 \\
Parênquima lacunoso & $49,03( \pm 12,93) \mathrm{a}$ & 26,37 & $46,25( \pm 9,82) \mathrm{a}$ & 21,23 \\
Epiderme abaxial & $13,84( \pm 1,83) \mathrm{a}$ & 13,24 & $13,45( \pm 2,35) \mathrm{a}$ & 17,50 \\
Espessura total & $143,40( \pm 22,76) \mathrm{a}$ & 15,87 & $137,17( \pm 15,57) \mathrm{a}$ & 11,35 \\
\hline
\end{tabular}

Aleric e Kirkman (2005), ao testarem o crescimento de Lindera melissifolia (Lauraceae), tanto em condições de viveiro quanto em condições naturais, verificaram que o peso seco não variou em resposta à quantidade de luz, porém tanto a área foliar quanto a área foliar específica diminuíram com o aumento dos níveis de luz e a densidade estomática foi significantemente maior em ambientes com alta disponibilidade de luz. Dessa forma, os autores afirmam que os resultados encontrados indicam que a planta é capaz de se aclimatar em condições onde ocorrem variações na luminosidade, através da plasticidade da morfologia foliar, e que ela apresentou um comportamento típico de resposta morfológica às diferenças impostas pelo crescimento no sol ou à sombra.

Os valores médios da espessura dos tecidos foliares são apresentados na tabela 2. Constatou-se que não houve diferença significativa na espessura total das folhas entre os tratamentos. Apesar disso, as 
espessuras da epiderme adaxial e do parênquima paliçádico mostraram ser significativamente maiores para as folhas da área aberta. Epidermes mais espessas, normalmente, são encontradas em folhas sob luz solar intensa, como uma estratégia para aumentar a reflexão dos raios luminosos (VOLGEMANN et al., 1996; SMITH et al., 1997) e assim proteger os tecidos sensíveis do mesofilo foliar contra o excesso de radiação (SULLIVAN et al., 1996).

As células do parênquima paliçádico possuem formato colunar, a fim de canalizar a luz, facilitando a sua penetração para o interior do mesofilo, e, geralmente em folhas que se desenvolvem sob iluminação intensa, possuem células parenquimáticas paliçádicas mais longas e com camadas adicionais (KERBAUY, 2004). O aumento da radiação solar influencia a divisão celular, o crescimento e a diferenciação celular (SANTIAGO et al., 2001). Morais et al. (2004) afirmam que em folhas de sol ocorre uma migração de auxinas para o interior do mesofilo, contribuindo com a distensão e o alongamento das células do parênquima paliçádico, o que gera maiores espessuras desse tecido.

Com relação ao parênquima lacunoso, os resultados apresentados mostram que ele não foi afetado pela diferença na quantidade de luz recebida em ambas as áreas. O parênquima lacunoso é um tecido formado por células de formato irregular, com uma alta proporção de espaços intracelulares, o que facilita a dispersão da luz, aumentando, dessa forma, a absorção desta pelos cloroplastos dentro do mesofilo (SMITH et al., 1997). Volgemann et al. (1996) afirmam que em ambientes com menor disponibilidade de luz, como o interior de florestas, as folhas apresentam maior desenvolvimento do parênquima lacunoso, pois ele é mais eficiente na distribuição da luz difusa no interior do mesofilo quando comparado com as células do parênquima paliçádico. Assim, o aumento nas camadas de parênquima lacunoso torna-se um mecanismo vantajoso de otimização da captura de luz, fato este não verificado com as folhas da bracatinga.

1

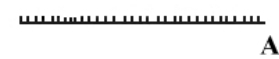

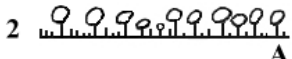

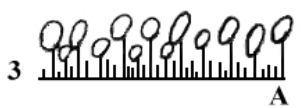

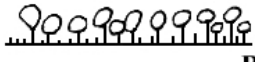
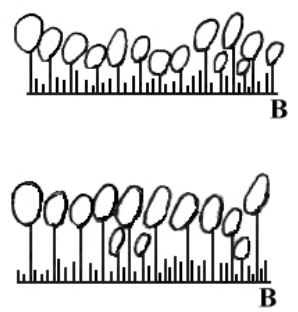

Figura 3. Perfil da evolução das duas áreas com diferentes graus de sucessão - Reservatório Iraí-PR. ( $\mathrm{A}$ = área aberta; $\mathrm{B}=$ capoeira. 1 = momento da implantação do experimento; 2 = áreas com 9 meses; 3 = áreas com 18 meses).

Figure 3. Overview of developments in two areas with different degrees of succession - Iraí's ReservoirPR. $(\mathrm{A}=$ open area; $\mathrm{B}=$ regenerating forest. 1 = time of deployment of the experiment; $2=$ areas of 9 months; $3=$ areas with 18 months).

O resultado da espessura total (Tabela 2) encontrada contradiz a literatura, que afirma que, normalmente, folhas de plantas crescidas sob pleno sol apresentam uma espessura maior do que aquelas de sombra (GIVNISH, 1988; LARCHER, 2000). Lee et al. (2000) verificaram que as folhas de mudas de Hopea odorata e $H$. helferi (Dipterocarpaceae) desenvolvidas sob maior irradiância apresentaram uma espessura maior que aquelas desenvolvidas sob baixa irradiância, e que essa diferença foi correlacionada com o aumento da espessura do parênquima paliçádico. Os autores afirmam que essa característica associada com a dureza (esclerofilia) pode ser muito importante para aumentar a força mecânica, reduzindo a herbivoria e aumentando a tolerância à seca. Justo et al. (2005) também verificaram que as folhas de Xylopia brasiliensis (Annonaceae) apresentaram espessura maior sob uma maior incidência de radiação solar, fato este que obteve correlação positiva com a assimilação de $\mathrm{CO}_{2}$. 
O plantio teve como objetivo recuperar a área degradada, motivo pelo qual não foi realizada nenhuma intervenção nela, à exceção de um coroamento aos seis meses. Logo, aos 18 meses já havia ocorrido a entrada de novas espécies e/ou indivíduos herbáceos-arbustivos, o que fez com que a área aberta estivesse bem mais sombreada, conforme pode ser evidenciado no perfil da vegetação ao longo do tempo (Figura 3). Apesar disso, no momento da coleta das folhas, a radiação fotossinteticamente ativa (P.A.R.) apresentou diferença significativa $(p>0,05)$ entre os tratamentos, e isso ocorreu, provavelmente, porque os indivíduos da bracatinga apresentavam, na média, uma altura muito superior à dos demais indivíduos presentes na área. Como a medição da P.A.R. é realizada na região apical da planta, isso fez com que continuasse havendo diferença na quantidade de luz entre os tratamentos. Porém vale chamar a atenção para o fato de que as mudas nesse momento são o reflexo de todo o tempo em que estão no campo, ou seja, expressam o produto de duas trajetórias de reocupação da área que se distinguem pelo seu ponto de partida.

Na tabela 3 podem ser vistos os valores médios referentes às características fisiológicas e, com exceção da taxa de fotossíntese líquida, que não obteve diferença significativa entre os tratamentos, todos os demais parâmetros (condutância estomática e transpiração) foram maiores e estatisticamente diferentes para a área aberta.

Os resultados da taxa de fotossíntese conflitam com a literatura, já que teorias clássicas (GIVNISH, 1988) afirmam que espécies adaptadas ou aclimatadas a habitats ensolarados exibem maiores taxas fotossintéticas e requerem mais luz para saturar a fotossíntese do que as espécies tolerantes a sombra. Reich et al. (1998) avaliaram as taxas de fotossíntese em nove espécies arbóreas boreais e verificaram que os resultados eram consistentes com tais teorias, afirmando que as taxas de fotossíntese foram maiores para as espécies intolerantes a sombra, verificando, também, que esse fato coincidiu com espécies pertencentes a estágios iniciais de sucessão e com aquelas com ciclos de vida menores.

Tabela 3. Valores médios, respectivos desvios-padrão (entre parênteses) e coeficientes de variação $(\mathrm{CV} \%)$ das características fisiológicas $(\mathrm{n}=30)$ para folhas de Mimosa scabrella nos diferentes tratamentos. Letras diferentes para mesma variável representam diferenças estatisticamente significativas entre os tratamentos testados (teste $\mathrm{t}, \mathrm{p}<0,05$ ).

Table 3. Averages, standard deviations (in parentheses) and coefficients of variation (CV\%) of the physiological characteristics $(\mathrm{n}=30)$ of Mimosa scabrella's leaves in different treatments. Different letters for the same variable represent statistically significant differences among the treatments tested ( $\mathrm{t}$ test, $\mathrm{p}<0,05$ ).

\begin{tabular}{lcccc}
\hline Características fisiológicas & Área aberta & CV $(\%)$ & Capoeira & CV (\%) \\
\hline Radiação fotossinteticamente ativa $\left(\mu\right.$ mol. $\left.\mathrm{m}^{-2} \cdot \mathrm{s}^{-1}\right)$ & $1387,5( \pm 455,23) \mathrm{a}$ & 32,81 & $935,27( \pm 526,62) \mathrm{b}$ & 56,31 \\
Fotossíntese líquida $\left(\mu \mathrm{mol} \cdot \mathrm{m}^{-2} \cdot \mathrm{s}^{-1}\right)$ & $3,84( \pm 2,88) \mathrm{a}$ & 74,88 & $2,88( \pm 1,99) \mathrm{a}$ & 69,03 \\
Condutância estomática $\left(\mathrm{mol} \cdot \mathrm{m}^{-2} \cdot \mathrm{s}^{-1}\right)$ & $0,11( \pm 0,08) \mathrm{a}$ & 76,02 & $0,07( \pm 0,05) \mathrm{b}$ & 72,46 \\
Transpiração $\left(\mathrm{mol} \cdot \mathrm{m}^{-2} \cdot \mathrm{s}^{-1}\right)$ & $1,62( \pm 0,78) \mathrm{a}$ & 48,06 & $1,20( \pm 0,72) \mathrm{b}$ & 60,19 \\
\hline
\end{tabular}

Os estômatos são encontrados somente na face abaxial da folha, ou seja, a bracatinga possui uma folha hipostomática. Smith et al. (1997) afirmam que a restrição dos estômatos na superfície inferior em folhas pode ter sido necessário para prevenir danos foto-oxidativos aos cloroplastos existentes nas células-guarda da epiderme. Além disso, estômatos no lado inferior de folhas em locais protegidos do vento estão expostos a muito mais umidade, devido aos efeitos flutuantes do vapor de água, de modo que a transpiração é substancialmente menor para o mesmo grau de abertura estomatal e ganho de $\mathrm{CO}_{2}$ para a fotossíntese.

De forma contrastante, Kubiske e Pregitzer (1997), ao estudarem as respostas ecofisiológicas de duas espécies arbóreas (Betula papyrifera e Acer rubrum) em condições de sol e sombra e com alta ou baixa quantidade de $\mathrm{CO}_{2}$, reportam que todos os tratamentos com aumentos na taxa fotossintética foram acompanhados de aumentos na condutância estomática. Os autores afirmam que uma mudança na condutância estomática pode ser resultado de variações nas aberturas estomáticas ou de uma mudança no número e/ou tamanho dos estômatos.

A transpiração foi significativamente maior na área aberta, corroborando com os estudos de Ashton e Berlyn (1992), que, ao estudarem as adaptações foliares em resposta ao sol e sombra de espécies 
do gênero Shorea, observaram que plantas de ambientes ensolarados tendem a apresentar maiores taxas fotossintéticas e de transpiração, devido às altas taxas de radiação fotossinteticamente ativa e de temperatura a que estão sujeitas. Esses autores afirmam ainda que todas as diferenças encontradas nos atributos fisiológicos sugerem que uma plasticidade maior é exibida pela maioria das espécies dependentes de luz e pela minoria das espécies tolerantes a sombra. Evans (1989) contradiz isso, afirmando que espécies tolerantes a sombra têm uma plasticidade fotossintética maior em resposta a variações da irradiância do que espécies intolerantes. Chazdon (1988) afirma que mudas do sub-bosque adaptadas a sombra podem sofrer uma rápida perda de turgescência e um fechamento estomatal quando completamente iluminadas por longos períodos de tempo, o que faz com que seu balanço diário de carbono seja limitado, afetando o recrutamento e a sobrevivência no sub-bosque.

Os dados referentes ao crescimento em altura e diâmetro encontram-se nas tabelas 4 e 5 . O diâmetro, ao longo dos 18 meses, não apresentou diferença significativa entre os tratamentos, enquanto que a altura aos seis e 12 meses foi significativamente maior para as mudas implantadas na capoeira, e aos 18 meses foi ligeiramente maior para a área de capoeira, porém essa diferença não é significativa.

Tabela 4. Valores médios, respectivos desvios-padrão (entre parênteses) e coeficientes de variação $(\mathrm{CV} \%)$ da altura $(\mathrm{cm})$ de Mimosa scabrella nos diferentes tratamentos. Letras diferentes para a mesma variável (mesma linha) representam diferenças estatisticamente significativas entre os tratamentos testados (Teste $\mathrm{t}, \mathrm{p}<0,05$ ).

Table 4. Averages, standard deviations (in parentheses) and coefficients of variation (CV\%) from Mimosa scabrella's height $(\mathrm{cm})$ in different treatments. Different letters for the same variable represent statistically significant differences among the treatments tested ( $t$ test, $\mathrm{p}<0,05)$.

\begin{tabular}{lcccc}
\hline Tratamento & Área aberta & CV $(\%)$ & capoeira & CV (\%) \\
\hline 6 meses & $35,11( \pm 12,69) \mathrm{b}$ & 36,15 & $39,92( \pm 15,50) \mathrm{a}$ & 38,83 \\
12 meses & $57,79( \pm 40,32) \mathrm{b}$ & 69,78 & $71,91( \pm 47,11) \mathrm{a}$ & 65,52 \\
18 meses & $104,09( \pm 77,62) \mathrm{a}$ & 74,58 & $128,05( \pm 75,52) \mathrm{a}$ & 58,98 \\
\hline
\end{tabular}

Tabela 5. Valores médios, respectivos desvios-padrão (entre parênteses) e coeficientes de variação (CV\%) do diâmetro (mm) de Mimosa scabrella nos diferentes tratamentos. Letras diferentes para mesma variável (mesma linha) representam diferenças estatisticamente significativas entre os tratamentos testados (teste $\mathrm{t}, \mathrm{p}<0,05$ ).

Table 5. Averages, standard deviations (in parentheses) and coefficients of variation (CV\%) from Mimosa scabrella's diameter $(\mathrm{mm})$ in different treatments.

\begin{tabular}{lcccc}
\hline Tratamento & Área aberta & $\mathbf{C V ~}(\%)$ & Capoeira & CV (\%) \\
\hline 6 meses & $4,33( \pm 1,67)$ a & 38,50 & $4,65( \pm 1,75)$ a & 37,64 \\
12 meses & $8,16( \pm 5,43)$ a & 66,55 & $8,41( \pm 4,95)$ a & 58,88 \\
18 meses & $13,33( \pm 9,29)$ a & 69,72 & $14,55( \pm 9,40)$ a & 64,62 \\
\hline
\end{tabular}

Tabela 6. Taxa de sobrevivência (\%) de Mimosa scabrella nos diferentes tratamentos.

Table 6. Survival rate (\%) of Mimosa scabrella in different treatments.

\begin{tabular}{lcc}
\hline Tratamento & Área aberta & Capoeira \\
\hline 6 meses & 53,2 & 63,24 \\
12 meses & 28 & 39,56 \\
18 meses & 18,33 & 26,79 \\
\hline
\end{tabular}

O rápido crescimento em ambiente sombreado é uma adaptação importante da espécie para minimizar o impacto resultante da baixa quantidade de luz (MORAES NETO et al., 2000). Outros autores afirmam que o crescimento maior em altura das plantas em ambientes com pouca disponibilidade de luz é uma resposta bastante comum, devido ao maior investimento no alongamento celular, visando a uma busca maior de luz, com maior quantidade de fotoassimilados na parte aérea (FRANCO; DILLENBURG, 2007). Dessa forma, nem sempre um crescimento maior em altura representa uma taxa de desenvolvimento eficiente, pois isso pode ser o reflexo de uma tendência ao estiolamento, ou seja, um investimento inicial pronunciado no alongamento vertical do caule a fim de alcançar a luz com maior 
facilidade. Steingraeber (1982) chama atenção para o fato de que um estiolamento pronunciado pode comprometer tanto a sustentação da parte aérea quanto o investimento em ramos laterais, por reduzir o vigor do caule.

Outro fato que chama a atenção é que, ao se analisar a altura, percebe-se, através do alto coeficiente de variação encontrado, que ocorreu uma heterogeneidade da amostra, ou seja, no experimento verificou-se a presença de algumas árvores muito altas (algumas alcançando $325 \mathrm{~cm}$ ), enquanto outras não ultrapassaram $40 \mathrm{~cm}$. Isso está de acordo com Aguiar (2006), que, ao realizar a modelagem do volume do povoamento de $M$. scabrella em bracatingais nativos da Região Metropolitana de Curitiba, afirma que a tendência com relação à altura dominante foi haver um coeficiente de variação maior dentro de bracatingais mais jovens, demonstrando assim a heterogeneidade desses bracatingais.

Por isso, o crescimento em diâmetro tem sido reportado como sendo um atributo mais sensível às condições ambientais de luz do que a altura (FAIRBAIRN; NEUSTEIN, 1970) e que níveis de incremento em diâmetro estão ligados com a expectativa de vida da muda, sendo que isso está relacionado com a tolerância a sombra (KOBE; COATES, 1997). Segundo Scalon et al. (2001), o aumento no diâmetro de caule sugere uma maior disponibilidade de fotoassimilados mobilizados pela parte aérea, ou seja, maior ganho de carbono, demonstrando, assim, um eficiente crescimento. Vale ressaltar que o crescimento do diâmetro de caule representa uma taxa de crescimento satisfatória e que a muda está aclimatada a determinada condição de irradiância, não sendo apenas o reflexo da busca pela luz, conforme evidenciado anteriormente no crescimento em altura.

Mason et al. (2004) estudaram a sobrevivência e o crescimento de mudas de coníferas com diferentes tolerâncias a sombra e verificaram que aquelas que cresceram em local aberto, ou seja, a pleno sol, apresentaram os maiores valores de altura e diâmetro, porém, taxas de sobrevivência não satisfatórias. Então, os autores questionam a suposição de que a luz seja o fator mais importante a influenciar o crescimento e a sobrevivência de mudas no sub-bosque, afirmando que ela somente será o fator principal em locais onde nem os nutrientes nem a precipitação sejam limitados. Complementam com a ideia de que esses outros fatores além da luz sejam mais problemáticos em locais de área aberta, nos quais a competição com espécies arbustivas é bem maior e as mudas estão mais suscetíveis a intempéries climáticas, como geadas.

M. scabrella tradicionalmente é classificada como uma espécie pioneira (REITZ et al., 1978; LORENZI, 1992; CARVALHO, 2003), e os resultados apresentados diferem entre uma série de autores (LEE et al., 2000), que afirmam que plantas sujeitas a ambientes mais heterogêneos apresentam maior plasticidade em resposta à luz, tais como espécies pioneiras, e que em espécies tolerantes a sombra a plasticidade de mesofilo normalmente é menor. Porém, para Yamashita et al. (2002), a plasticidade não pode ser generalizada, como sempre ocorrendo, em apenas uma categoria sucessional de plantas e que algumas características são mais plásticas nos estágios sucessionais primários, enquanto que outras se manifestam principalmente em estágios sucessionais tardios. Os mesmos autores, ao estudarem se espécies de diferentes estágios sucessionais tinham a habilidade de aclimatação em resposta a condições lumínicas distintas durante a ontogenia foliar, perceberam que as características plásticas não são somente influenciadas ao longo do gradiente sucessional, mas também podem ser influenciadas pela idade das folhas. Nesse caso, uma maior plasticidade em espécies pioneiras do que nas tardias somente foi verificado em folhas que tinham acabado de se expandir completamente (folhas ainda jovens). Quando se tratava de folhas mais velhas (maduras), a plasticidade foliar foi maior na espécie de estágio sucessional tardio (Elaeocarpus photiniaefolius) do que na espécie pioneira (Trema orientalis). Logo, é provável que as diferenças na plasticidade fenotípica entre folhas de sol e sombra sejam consideravelmente dependentes do tempo de maturidade fisiológica de cada espécie associado à categoria sucessional a que esta pertence.

Outro fator a se considerar é que espécies pioneiras possuem uma taxa de renovação foliar e capacidade fotossintética maior que as espécies secundárias ou tardias, porém são mais suscetíveis a herbivoria, já que são menos esclerófilas e possuem mais nutrientes. Logo, a presença de uma taxa fotossintética maior, a qual proporciona um ganho maior de carbono, vem a compensar o estresse causado pela herbivoria, minimizando qualquer perda causada por ela (YAMASHITA et al., 2002).

A alta taxa de mortalidade encontrada (Tabela 6) é reforçada por Carpanezzi et al. (1988), os quais afirmam que a mortalidade da bracatinga em idades jovens é característica intrínseca da espécie, porém outros fatores podem ter contribuído para essa alta taxa de mortalidade, como o fato de a 
bracatinga ser uma espécie que não tolera geada. Estudo realizado na Costa Rica (LAURENT et al., 1990) mostrou que a competição com plantas invasoras, a compactação e a deficiência de fósforo no solo foram os fatores limitantes para a sobrevivência da bracatinga, assim como solos mal drenados.

O comportamento natural dessa espécie é outro fator que deve ser levado em consideração, pois a bracatinga possui regeneração natural em grande número seguido de alta mortalidade, chegando a alcançar, em certas áreas, segundo Carpanezzi (1988), 80 a 100 mil indivíduos por hectare. Reitz et al. (1988) afirmam que o desenvolvimento da bracatinga em plantios experimentais, com espaçamentos variáveis, é bom quando se mantém de 2.000 a 2.500 plantas por hectare, apresentando, nessas condições, um desenvolvimento bastante expressivo, principalmente em altura. Porém Tonon (1998) sugere deixar 4 mil plantas por hectare como densidade inicial para novos povoamentos, para que o recobrimento da área seja efetivo.

Também se registra no Reservatório do Iraí a presença em grande quantidade de capivaras (Hydrochaeris hydrochaeris), as quais possuem como hábito alimentar a herbivoria. Principalmente na coleta de dados dos seis meses foi visível a predação em muitas mudas de bracatinga. Forero-Montaña et al. (2003) afirmam que esses mamíferos roedores apresentam preferências por determinadas famílias de plantas, e ao fazer um estudo sobre a dieta desses animais na Colômbia, relataram que a família Leguminosae foi a terceira família mais procurada, com referência ao gênero Mimosa sp.

Por último, deve ser ressaltada a estrutura de copa da bracatinga. Em estudo para verificar o crescimento e nutrição de algumas espécies leguminosas, Coelho et al. (2007) verificaram que a bracatinga apresentou um baixo valor de biomassa de folhas aos dois anos, mas produziu maior quantidade de lenho, indicando um menor dispêndio de fotoassimilados para síntese de ramos. Ao relacionar esse fato com o comportamento natural da espécie, que ocorre em alta densidade populacional, os autores chamam a atenção para o fato de a bracatinga ser uma espécie que apresenta folhas muito pequenas e concentradas nas extremidades dos ramos, característica esta que lhe confere maior flexibilidade na busca por espaço luminoso e diminui o sombreamento interespecífico. Essa capacidade superior de competição interespecífica da bracatinga pode ter sido prejudicada pelo plantio misto, ou seja, a forma da copa das outras espécies utilizadas no experimento podem ter proporcionado um sombreamento maior ao tolerável pelas mudas de bracatinga, contribuindo para a alta taxa de mortalidade verificada com a espécie.

Dessa forma, sempre que possível, os modelos de regeneração devem simular a condição natural, ou seja, utilizar metodologias que busquem recompor a área de forma que os processos sucessionais ocorram no ambiente, proporcionando o surgimento de uma biodiversidade compatível com o que seria obtido através de condições naturais, sem a interferência do homem.

Com base nos resultados apresentados, ou seja, a baixa variação da área foliar, da espessura foliar, da altura, dos diâmetros médios e da taxa fotossintética e a baixíssima taxa de sobrevivência verificada em ambos os tratamentos, conclui-se que $M$. scabrella não obteve resultados satisfatórios para crescer nas áreas que apresentavam as duas condições ofertadas de disponibilidade de luz ao longo do tempo, mostrando que ela, nesse caso, possui baixa plasticidade de resposta em função da variação de irradiância ao longo de seu desenvolvimento. Portanto, M. scabrella, quando implantada, deve ser utilizada em altas densidades ou com procedimentos que conduzam a essa densidade mais alta, tal qual como a semeadura direta com grande número de sementes por área ou ainda através do aproveitamento de banco de sementes.

\section{REFERÊNCIAS}

ALERIC, K. M.; KIRKMAN, L. K. Growth and photosynthetic responses of the federally endangered shrub, Lindera melissifolia (Lauraceae), to varied light environments. American Journal of Botany, St. Louis, v. 92, n. 4, p. 682 - 689, 2005.

AGUIAR, L. P. Modelagem do volume do povoamento de Mimosa scabrella Benth. em bracatingais nativos da região metropolitana de Curitiba. 2006. 120 f. Dissertação (Mestrado em Engenharia Florestal) - Universidade Federal do Paraná, Curitiba, 2006. 
ALVES, A. C. A. Efeito das diferentes intensidades luminosas na morfoanatomia foliar de duas espécies de plantas medicinais em consórcio com Ilex paraguariensis A. St.-Hil. (Aquifoliaceae). 2006. 61 f. Dissertação (Mestrado em Botânica) - Universidade Federal do Paraná, Curitiba, 2006.

ASHTON, P. M. S.; BERLYN, G. P. Leaf adaptations of some Shorea species to sun and shade. New Phytologist, Cambridge, v. 121, p. 587 - 596, 1992.

BERTALOT, M. J. A.; GUERRINI, I. A.; MENDONZA, E.; DUBOC, E.; BARREIROS, R. M.; CORRÊA, F. M. Retorno de nutrientes ao solo via deposição de serapilheira de quatro espécies leguminosas arbóreas na região de Botucatu, São Paulo, Brasil. Scientia Forestalis, n. 65, p. 219 - 227, 2004.

BOEGER, M. R. T.; KAEHLER, M.; MELO JÚNIOR, J. C. F.; GOMES, M. Z.; OLIVEIRA, L. S.; CHAVES, C. R. M.; SCHOTTZ, E. S. Estrutura foliar de seis espécies do sub-bosque de um remanescente de Floresta Ombrófila Mista. Hoehnea, v. 33, n. 4, p. 521 - 531, 2006.

BONGERS, F.; POPMA, J. Leaf characteristics of the tropical rain forest flora of Los Tuxtlas, Mexico. Botanical Gazette, v. 151, p. 354 - 365, 1990.

BUDOWSKI, A. Distribution of tropical american rain forest species in the light of successional progresses. Turrialba, v. 15, p. 40 - 42, 1965.

CAMPELO, E. F. C. Sucessão vegetal na recuperação de áreas degradadas. In: DIAS, L. E.; MELLO, J. W. V. Recuperação de áreas degradadas. Viçosa: UFV, 1998. p. 183 - 196.

CARNEIRO, C.; PEGORINI, E. S.; ANDREOLLI, C. V. Introdução. In: ANDREOLLI, C. V.; CARNEIRO, C. (Ed.). Gestão integrada de mananciais de abastecimento eutrofizados. Curitiba: Gráfica Capital, 2005. p. 25 - 44.

CARPANEZZI, A. A.; IVANCHECHEN, S. L.; LISBÃO JÚNIOR, L. Deposição de matéria orgânica e nutrientes por bracatinga (Mimosa scabrella Benth.). Curitiba: EMBRAPA-URPFCS, 3 p., 1984.

CARPANEZZI, A. A. (Org.). Manual técnico da bracatinga (Mimosa scabrella Bentham). Curitiba: EMBRAPA-CNPF, 1988. 70 p. Documentos 20.

CARPANEZZI, A. A.; PAGANO, S. N.; BAGGIO, A. J. Banco de sementes de bracatinga em povoamentos do sistema agroflorestal tradicional de cultivo. Boletim de Pesquisa Florestal, Colombo, n. 35, p. 3 - 19, 1997

CARVALHO, P. E. R. Espécies arbóreas brasileiras. Colombo: Empresa Brasileira de Pesquisa Agropecuária, Centro Nacional de Pesquisa de Florestas, 2003. 640 p.

COELHO, S. R. F.; GONÇALVES, J. L. M.; MELLO, S. L. M.; MOREIRA, R. M.; SILVA, E. V.; LACLAU, J. P. Crescimento, nutrição e fixação biológica de nitrogênio em plantios mistos de eucalipto e leguminosas arbóreas. Pesquisa Agropecuária Brasileira, Brasília, v. 42, n. 6, p. 759 - 768, 2007.

CORRÊA, I. J. Plasticidade fenotípica em indivíduos jovens de Aloysia virgata (Ruiz et Pav.) A. L. Juss - Verbenaceae. 2004. 58 f. Dissertação (Mestrado) - Universidade Federal de São Carlos, São Carlos, 2004.

CURCIO, G. R.; SOUSA, L. P.; BONNET, A.; BARDDAL, M. L. Recomendação de espécies arbóreas nativas, por tipo de solo, para recuperação ambiental das margens do rio Iraí, Pinhais, PR. Revista Floresta, v. 37, n. 1, p. 113 - 122, 2007.

DALE, J. E. The control of leaf expansion. Annual Review of Plant Physiology, Palo Alto, v. 39, p. 267 295, jan. 1988.

DENSLOW, J. S. Gap partioning among tropical rain forest trees. Biotropica, v. 12, p. 47 - 55, 1980.

DICKSON, W. C. Integrative plant anatomy. San Diego: Horcant Academy Press, 2000.

DURIGAN, G.; MELO, A. C. G.; CONTIERI, W. A.; NAKATA, H. Regeneração natural da vegetação de cerrado sob florestas plantadas com espécies nativas e exóticas. In: BÔAS, O. V.; DURIGAN, G. (Org.) Pesquisas em conservação e recuperação ambiental do oeste paulista: resultados da cooperação Brasil/Japão/Instituto Florestal. São Paulo: Páginas \& Letras Editora e Gráfica, 2004. p. 447 - 456. 
EMPRESA BRASILEIRA DE PESQUISA AGROPECUÁRIA (EMBRAPA) Centro Nacional de Pesquisa de Solos. Sistema brasileiro de classificação de solos. Rio de Janeiro, 1999. 412 p.

EVANS, J. R. Photosynthesis and nitrogen relationships in leaves of $\mathrm{C}_{3}$ plants. Oecologia, v. 78, p. 9 19, 1989.

FAIRBAIRN, W. A.; NEUSTEIN, S. A. Study of response of certain conifers to light intensity. Forestry, v. 43, p. $57-71,1970$.

FERREIRA, L. A. B. Arborização dos cursos d'água. Trigo e Soja, Porto Alegre, n. 68, p. 16 - 21, 1983.

FERREIRA, C. A. G.; TAUK-TORNISIELO, S. M.; CHAVES, M. M. F. Comportamento de bracatinga (Mimosa scabrella) e sesbânia (Sesbania sesban) em áreas degradadas pela disposição de resíduos provenientes do processamento da bauxita. Holos Environment, v. 2, n. 2, p. 156 - 173, 2002.

FORERO-MONTAÑA, J.; BETANCUR, J.; CAVELIER, J. Dieta del capibara Hydrocharis hydrochaeris (Rodentia: Hydrochaeridae) en Cano Limón, Arauca, Colombia. Revista de Biologia Tropical, San Jose, v. 51, n. 2, p. 579 - 590, jun. 2003.

FRANCO, A. M. S.; DILLENBURG, L. R. Ajustes morfológicos e fisiológicos em plantas jovens de Araucaria angustifolia (Bertol.) Kuntze em resposta ao sombreamento. Hoehnea, v. 34, n. 2, p. 135 - 144, 2007.

GIVNISH, T. J. Adaptation to sun and shade: a whole-plant perspective. Aust. J. Plant Physiol., v. 15, p. $63-92,1988$.

GONÇALVES, J. F. de C.; VIEIRA, G.; MARRENCO, R. A.; FERRAZ, J. B.; JÚNIOR, U. M. dos S.; BARROS, F. C. Nutricional status and specific leaf area of mahogany and tonka beans under two light environments. Acta Amazônica, Manaus, v. 35, n. 1, p. 23 - 27, 2005.

GRIME, J. P.; MACKEY, J. M. L. The role of plasticity in resource capture by plants. Evolutionary Ecology, v. 16, p. 299 - 307. 2002.

JOHANSEN, D. A. Plant microtechnique. New York: McGraw Hill Book, 1940.

JUSTO, C. F.; SOARES, A. M.; GAVILANES, M. L.; CASTRO, E. M. Plasticidade anatômica das folhas de Xylopia brasiliensis Sprengel (Annonaceae). Acta Botânica Brasilica, v. 19, n. 1, p. 111 - 123, 2005.

KAGEYAMA, P. Y. Conservação "in situ” de recursos genéticos de plantas. IPEF, Piracicaba, n. 35, p. 7 - 37 , abr. 1987.

KERBAUY, G. B. Fisiologia vegetal. São Paulo: Editora Guanabara Koogan, 2004. 472 p.

KLICH, M. G. Leaf variations in Elaeagnus angustifolia related to environmental heterogeneity. Environmental and Experimental Botany, v. 44, p. 171 - 183, 2000.

KOBE, R. K.; COATES, K. D. Models of sapling mortality as a function of growth to characterize interspecific variation in shade tolerance of eight tree species of northwestern British Columbia. Canadian Journal of Forest Research, v. 27, n. 2, p. 227 - 236, 1997.

KUBISKE, M. E.; PREGITZER, K. S. Ecophysiological responses to simulated canopy gaps of two tree species of contrasting shade tolerance in elevated $\mathrm{CO}_{2}$. Functional Ecology, v. 11, p. 24 - 32, 1997.

LARCHER, W. Ecofisiologia vegetal. São Carlos: RiMa, 2000. 531 p.

LAURENT, J. M. E.; MENDONÇA, W. R. de. A comercialização dos produtos do sistema bracatinga na região metropolitana de Curitiba. Curitiba, 1990. 46 p. Projeto FAO-GCP/BRA/025/FRA, Convênio BRASIL/Paraná - FRANÇA-FAO.

LEE, D. W.; OBERBAUER, S. F.; JOHNSON, P.; KRISHNAPILAY, B.; MANSOR, M.; MOHAMAD, H.; YAP, S. K. Effects of irradiance and spectral quality on leaf structure and function in seedlings of two southeast Asian Hopea (Dipterocarpaceae) species. American Journal of Botany, St Louis, v. 87, n. 4, p. $447-455,2000$. 
LORENZI, H. Árvores brasileiras: manual de identificação e cultivo de plantas arbóreas nativas do Brasil. Nova Odessa: Plantarum, 1992. 352 p.

MAACK, R. Geografia física do estado do Paraná. 2. ed. Curitiba: Ed. Olympio, 1981. 450 p.

MASON, W. L.; EDWARDS, C.; HALE, S. E. Survival and early seedling growth of conifers with different shade tolerance in a Sitka spruce spacing trial and relationship to understorey light climate. Silva Fennica, Helsinki-Finland, v. 38, n. 4, p. 357 - 370, 2004.

MEZIANI, D.; SHIPLEY, B. Interacting determinants of specific leaf area in 22 herbaceous species: effects of irradiance and nutrient availability. Plant, Cell and Environment, v. 22, p. 447 - 459, 1999.

MORAES NETO, S. P.; GONÇALVES, J. L. M.; TAKAKI, M.; CENCI, S.; GONÇALVES, J. C. Crescimento de mudas de algumas espécies arbóreas que ocorrem na Mata Atlântica em função do nível de luminosidade. Revista Árvore, Viçosa, v. 24, n. 1, p. 35 - 45, 2000.

MORAIS, H.; MEDRI, M. E.; MARUR, C. J.; CARAMORI, A. M. de A. R.; GOMES, J. C. Modifications on leaf anatomy of Coffea arabica caused by shade of Pigeonpea (Cajanus cajan). Brazilian Archives of Biology and Technology, Curitiba, v. 47, n. 6, p. 863 - 871, 2004.

NOGUEIRA, A. C. Coleta, manejo, armazenamento e dormência de sementes. In: GALVÃO, A. P. M.; MEDEIROS, A. C. S. (Ed.). Restauração da Mata Atlântica em áreas de sua primitiva ocorrência natural. Colombo: Embrapa Florestas, 2002. p. 45 - 52.

POORTER, L. Growth responses of 15 rain-forest tree species to a light gradient: the relative importance of morphological and physiological traits. Functional Ecology, v. 13, p. 396 - 410, 1999.

Light-dependent changes in biomass allocation and their importance for growth of rain forest tree species. Functional Ecology, Londres, v. 15, p. 113 - 123, 2001.

REICH, P. B.; WALTERS, M. B.; TJOELKER, M. G.; VANDERKLEIN, D.; BUSCHENA, C. Photosynthesis and respiration rates depend on leaf and root morphology and nitrogen concentration in nine boreal tree species differing in relative growth rate. Functional Ecology, v. 12, p. 395 - 405, 1998.

REIS, A.; BECHARA, F. C.; ESPÍNDOLA, M. B.; VIEIRA, N. K.; SOUZA, L. L. Restauração de áreas degradadas: a nucleação como base para incrementar os processos sucessionais. Natureza \& Conservação, v. 1, n. 1, p. 28 - 36, 2003.

REITZ, R.; KLEIN, R. M.; REIS, A. Projeto madeira de Santa Catarina. Itajaí: Instituto Brasileiro de Desenvolvimento Florestal, IBDF, 1978. 320 p.

Projeto madeira do Rio Grande do Sul. Porto Alegre: Secretaria da Agricultura e Abastecimento, 1988. 525 p.

RICKLEFS, R. E. A economia da natureza. Rio de Janeiro: Guanabara Koogan, 2003. 503 p.

RODRIGUES, R. R.; GANDOLFI, S. Restauração de florestas tropicais: subsídios para uma definição metodológica e indicadores de avaliação e monitoramento. In: DIAS, L. E.; MELLO, J. W. V. Recuperação de áreas degradadas. Viçosa: UFV, 1998. 251 p.

SANTIAGO, E. J. A.; PINTO, J. E. B. P.; CASTRO, E. M.; LAMEIRA, O. A.; CONCEIÇÃO, H. E. O.; GAVILANES, M. L. Aspectos da anatomia foliar da pimenta-longa (Piper hispidinervium C. D. C.) sob diferentes condições de luminosidade. Ciência e Agrotecnologia, Lavras, v. 25, n. 5, p. 1035 - 1042, 2001.

SCALON, S. P. Q.; SCALON FILHO, H.; RIGONI, M. R.; VERALDO, F. Germinação e crescimento de mudas de pitangueira (Eugenia uniflora L.) sob condições de sombreamento. Revista Brasileira de Fruticultura, v. 23, n. 3, p. 652- 655, 2001.

SMITH, W. K.; VOGELMANN, T. C.; DELUCIA, E. H.; BELL, D. T.; SHEPHERD, K. A. Leaf form and photosynthesis: do leaf structure and orientation interact to regulate internal light and carbon dioxide? Bioscience, Washington, v. 47, n. 11, p. 785 - 793, 1997. 
STEINGRAEBER, D. A. Phenotypic plasticity of branching pattern in sugar maple (Acer saccharum). American Journal of Botany. v. 69, n. 4, p. 638 - 640, 1982.

STRAUSS-DEBENEDETTI, S.; BAZZAZ, F. Photosynthetic characteristics of tropical trees along sucessional gradients. In MULKEY, S. S.; CHAZDON, R. L.; SMITH, A. P. (Ed.). Tropical forest plant ecophysiology. New York: Chapman \& Hall, 1996. p. 162 - 186.

SUlLIVAN, J. H.; HOWELLS, B. W.; RUHLAND, C. T.; DAY, T. A. Changes in leaf expansion and epidermal screening effectiveness in Liquidambar styraciflua and Pinus taeda in response to UV-B radiation. Physiologia Plantarum, v. 98, p. 349 - 357, 1996.

TONON, A. E. N. Efeitos da densidade inicial e do sítio sobre o crescimento e a produção de bracatingais da região metropolitana de Curitiba. 209 f. Dissertação (Mestrado em Manejo Florestal) - Universidade Federal do Paraná, Curitiba, 1998.

VELOSO, H. P.; RANGEL FILHO, A. L. R.; LIMA, J. C. A. Classificação da vegetação brasileira, adaptada a um sistema universal. Rio de Janeiro: IBGE, Departamento de Recursos Naturais e Estudos Ambientais, 1991. 124 p.

VOLGEMANN, T. C.; NISHIO, J. N.; SMITH, W. K. Leaves and light capture: light propagation and gradients of carbon fixation within leaves. Trends in Plant Science, Oxford, v. 1, n. 2, p. 65 - 70, 1996.

WITKOWSKI, E. T. F.; LAMONT, B. B. Leaf specific mass confounds leaf density and thickness. Oecologia, v. 88, p. 486 - 493, 1991.

YAMASHITA, N.; KOIKE, N.; ISHIDA, A. Leaf ontogenetic dependence of light acclimation in invasive and native subtropical trees of different sucessional status. Plant, Cell and Environment, v. 25, n. 10, p. 1341 - 1356, 2002.

YARRANTON, R. J.; MORRISON, R. G. Spatial dynamics of a primary sucession: nucleation. Journal of Ecology, v. 62, n. 2, p. $417-428,1974$. 
